\title{
'Children aren't Standardized, they are Unique': Using Bourdieu to Expose the Complexity behind Educational Outcomes of Looked-After Children
}

\author{
Gary Walker \\ Leeds Beckett University, England
}

\begin{abstract}
Formal educational outcomes of looked-after children in England are lower compared to their peers not in care. The dominant research and policy discourse positions looked-after children as failing, and links this with the attitudes and behaviour of staff who support these children. Alternative approaches suggest the need to consider more complex factors such as the long-term impact of precare experiences and the inherent limitations of substitute care. The Bourdieusian concepts of capital, field and habitus, together with the neoBourdieusian notion of institutional habitus, provide a relevant theoretical framework for deepening understanding of mechanisms behind social reproduction. This paper therefore explores the extent to which the role of the care system might be better understood using these theoretical lenses, particularly that of institutional habitus. For the research reported on, twenty-eight education and social care professionals working within two local authorities, and two care leavers, took part in individual and group interviews. The findings indicate that a complex set of factors help explain educational outcomes of looked-after children. Staff were keenly aware of the individual needs of the children with whom they worked, and made efforts to balance the socio-emotional needs of the children with their educational needs, within a context in which structural forces resulted in barriers and standardized expectations that impinged upon the work of the staff.
\end{abstract}

\section{Introduction}

In England, over many years, the school test and examination results of looked-after children (also referred to as children in care) have remained significantly lower than their peers not in care. There has been a significant body of research searching for possible causes of the persistent gap in outcomes, and therefore also for possible solutions [1]. This can be summarized into two main positions. The dominant policy discourse places responsibility for the attainment gap between looked-after children and their peers not in care, on what is seen as a 'failing' care system, and details areas that social workers, teachers, carers and others might improve upon in order to achieve the goal of better test and examination outcomes [2].

Proponents of the alternative discourse such as Berridge [1] argue that it may be unreasonable to expect the care system to compensate fully for the long-term impact of early abuse and disadvantage which many looked-after children experience, and that these pre-care factors may have a deeper influence upon the educational trajectory of lookedafter children than factors associated with the care system.

The starting point for the research reported upon in this paper was to view the educational outcomes of looked-after children as a problem of social reproduction: low achievement, whatever the reason, impairs the life chances of looked-after children. Pierre Bourdieu has developed a compelling framework for understanding how social inequalities might be sustained over generations, through his work on the acquisition of different forms of capital [3], the development of individual habitus [4], on how habitus operates in relation to the field of education [5], and on how these three work dynamically together. More recently the neoBourdieusian notion of institutional habitus provides further insight into mechanisms supporting social reproduction at the level of the institution [6]. The research discussed in this paper employed his ideas because it was seen as important to study the broader context, including the inherent limitations of substitute care, independent of the quality of care given, and the application of Bourdieu's ideas offers insight into this.

Of the four types of capital identified by Bourdieu [3], which are economic capital, social capital, symbolic capital and cultural capital, the research study reported upon in this paper focused on two components of cultural capital. First, embodied cultural capital includes internalized characteristics such as customs, manners, knowing how to behave within dominant cultural spheres, and a culturally esteemed accent or vocabulary which can bring advantage to individuals. It is important to note that in addition to the disadvantage resulting from the absence of cultural capital, even more limiting 
negative capital can follow from, for example, particular accents or personal characteristics. Second, institutionalized cultural capital is comprised of educational qualifications which are recognized by those who legitimate them as being valuable for advancement. Thus young people who leave school with what are seen as the appropriate educational outcomes are immediately at an advantage compared to those young people who have not achieved these qualifications.

Capital only comes into play within a field. A field is not a benign, neutral space, but instead is better characterized as a field of forces within which there are 'struggles for power among the holders of different forms of power' [5]. Within such fields, there is competition for capital which is considered dominant and advantageous. However, those already holding power possess more efficacious cultural capital, and therefore the status quo of social inequality tends to be reproduced and maintained. In addition, according to Bourdieu [3] there is a further vital process at play here: that of individual habitus. This is formed as a response to early experience when individuals internalize their social situation, and this in turn influences how they are then disposed to the social world.

The habitus, Bourdieu argues, is a powerful internal structure that is both structured by experience, and which structures future expectation and behaviour. The habitus works at the level of the unconscious to influence dispositions towards different aspects of the social world, such as attitudes to school, or career aspiration and possibilities. Crucially, the habitus is rooted in the internalized social class experience of the individual, and therefore acts as a powerful force when that individual enters a different social space.

For example, when a child enters the field of the school, Bourdieu and Wacquant [7] argue that the child moves into a space loaded in favour of the advantaged, since the school's culture and practices reflect middle-class life. Thus a middle-class child, 'encounters a social world of which it is a product, it is like a "fish in water": it does not feel the weight of the water and it takes the world about itself for granted' [7].

However, for working-class children, the experience is more daunting and disquieting, since their habitus causes them to feel out of place. Thus, from the very beginning, their progress through the school journey is structurally inhibited, irrespective of any innate ability the child may possess. In this way, Bourdieu and Wacquant argue, education tends to act as a reproductive rather than a transformative process.

Based on the idea that organisations can also form powerful dispositions which are shared by those working within them, the concept of habitus has in more recent years been extended to institutions. Thus, institutional habitus has been defined as the organization's 'relational issues and priorities, which are deeply embedded, and subconsciously informing practice' [8]. Here, institutions are seen as acquiring and absorbing aspects of the social, economic and political world in which they operate, just as individuals do within the concept of individual habitus. This then results in a powerful institutional disposition, shared and enacted by those working within the institution. The research described in this paper, which took place in England, uses this Bourdieusian lens of institutional habitus to explore the role of staff supporting looked-after children, within their organizational context.

\section{Literature Review}

Predicated on the assumption that those taking over responsibility for looked-after children should be able to compensate for any early disadvantage these children have experienced, most of the mainstream research in England focuses on the attitudes of those supporting looked-after children, such as social workers, teachers and carers. There are several findings reported. In one study, thirty-eight looked-after children were interviewed, and they reported that those supporting them failed to place sufficient importance upon help with homework and developing new interests and hobbies [2]. Furthermore, the same study reported negative stereotypes and low expectations amongst professionals supporting the looked-after children.

The relatively low sample size here, and the lack of triangulation of the data (by failing to include other groups of participants, for instance) mean that the results reported upon may not be representative of the general population of looked-after children. A second study took a more robust approach to the research design by collecting data from 377 lookedafter children, carrying out deep case studies with seven children, and interviewing social workers and school staff [9]. The authors concluded that low expectations were prevalent among professionals, and that there was a need therefore to reverse this in order to encourage looked-after children to achieve better educational outcomes.

Similar findings emerged from a third study which consisted of a one-year research project in Scotland [10]. The research involved a retrospective sample of fourteen children (in care for at least two years at the start of the study) and a prospective sample of thirteen children (in care for six weeks at the start of the study). In addition to studying case records of the children, the researcher administered questionnaires to teachers (the $\mathrm{n}$ is not specified), social workers $(n=11)$ and carers $(n=10)$, and interviewed seven children. The study reported that the attitudes and perceptions of teachers (low 
expectations), and of social workers and carers (insufficient prominence given to education) were key barriers for the looked-after children, and that within school, there was evidence that teachers failed to manage behavioural problems of looked-after children effectively. Taken together, the prevailing research findings appear to demonstrate how the attitudes and behaviour of adults supporting lookedafter children contribute to the educational failure of those children who do not achieve the same examination outcomes as their peers who are not in care. Nevertheless, it is worth remembering, in addition to the inherent danger of over-generalizing from isolated research studies, that there is a risk of conflating correlation with causation. The existence of reported low expectations or lack of support among staff working with looked-after children and the parallel existence of lower test and examination outcomes of looked-after children does not automatically mean that there is a causal relationship between the two. There are many factors that may be at play, influencing the performance of looked-after children within the narrow confines of a test or examination context.

Some of these factors have been identified within the body of literature that has began to emerge in opposition to the more dominant research described above. Berridge [1] argues that the circumstances of looked-after children are deeply complex and structural in origin. Many of the factors that lookedafter children experience before entering care are closely associated with poor educational outcomes, even among children who remain with their birth parents. The poverty and social disadvantage these children face, and the long-term impact of this, may have been downplayed by the researchers focusing upon the role of adults supporting looked-after children. Furthermore, the normative practice of comparing educational outcomes for looked-after children with those of their peers not in care risks losing sight of the fact that such a comparison is itself flawed.

Given the very different backgrounds of the two groups, and the damaging pre-care experiences of looked-after children compared to children not in care, it might be considered strange if there were no impact upon the educational performance of the former group. It may be more pertinent and meaningful, therefore, to examine the educational progress made by looked-after children once they enter care, and to take this as a more valid measure of success. Several other authors have also concluded that the disadvantaged backgrounds that many looked-after children experience prior to entering care have a long-term impact upon them. Coman and Devaney [11] argue for what they call an ecological approach in understanding outcomes for looked-after children which takes into account the inter-play between pre-care and in-care experiences, the disposition of the child upon entering care (for instance, whether they are relieved or resistant), intra-agency and inter-agency relationships, and societal level issues such as poverty, policy and resourcing to support looked-after children. They concluded that many looked-after children have difficulty forming relationships, including with those adults who are trying to help and advise them, and that this can impact negatively upon their progress.

Other research has identified the presence of ongoing mental health problems among looked-after children as a key factor in contributing to less successful outcomes [12]. The relatively high prevalence of special educational needs, including behavioural problems, has also been cited as worthy of note [13]. Berridge [1] makes the point that over one quarter of looked-after children have ongoing special educational needs compared to only about $3 \%$ of the general school population, and that this inevitably impacts upon their educational prowess.

Where the pre-care experiences of looked-after children specifically include abuse and neglect, this can have long-term consequences for looked-after children. In one study, seventeen looked-after children were compared with seventeen of their peers living at home, with the conclusion that early attachment and relationship difficulties experienced by the former group resulted in less coherence and organization of psychological functioning, which itself then impacted upon the children's learning potential [14]. A further study of 102 looked-after children found that 32 of them reported actual or potential self-harm, and that across all the participants, lower academic self-esteem was an issue, being more prevalent among the group that reported self-harm [15]. The long-term impact of early disadvantage, abuse and neglect upon attention and memory functioning was the focus of a paper by Phillips [16]. She argues that this effect can occur in two different ways. First, physical brain development can be detrimentally affected. Second, post traumatic stress disorder, and the effects of attachment disorder, can lead to emotional and behavioural problems.

In short, children entering care are likely to have a level of long-lasting mental ill-health, learning problems associated with attention and memory deficits, and behavioural difficulty, including the inability to trust those very adults who are trying to help and support them.

Importantly, these effects, and lower educational attainment of looked-after children, appear to exist even in countries with relatively plentiful resources to support looked-after children such as Canada, Germany, Sweden, Belgium, Norway and Spain, and where better outcomes might be expected if the assumption that the care system should be able to compensate is correct [17]. Perhaps this finding helps to highlight the limitations of substitute care 
per se, irrespective of how well-resourced is the care system that surrounds the child.

The Bourdieusian framework used in the research that forms the basis of this paper helps to navigate the two positions described above. The quote within the title of this paper is taken from a participant in the research, and reflects the tension between the use of 'standardized' and normative measures and the importance of recognizing the unique biographies and trajectories of each child. While it is important to consider the attitudes of workers who support looked-after children, and the impact these may have upon the children, it is equally vital to consider the role of the care system, at the level of the local authority as a whole, in relation to the reproduction of social inequality in the form of educational outcomes of looked-after children.

This is where the lens of institutional habitus was helpful in formulating the basis of the research approach. A more holistic approach which considers not only the attitudes of staff at the surface level to the looked-after children, but explores also the deeper motivations and internalised dispositions of staff towards the children, working within the context of organizational imperatives at local authority level, was likely to yield interesting findings.

Accordingly, the research questions focused upon exploring, among those who support looked-after children, the dispositions towards and enactments of national and local policies, the dominant assumptions and conceptualizations of looked-after children, how educational achievement is understood and enacted, how individual and institutional levels of practice are related, and how the relationships between different services that support looked-after children are characterized.

\section{Methodology}

Two local authorities in England were purposively chosen as loci for the research, due to their differing characteristics. The first, called Municipal, serves a city and its immediate district with a population over 500000 people. It covers a relatively small, densely populated geographical area. The number of looked-after children is in excess of 500. In the three years prior to the research taking place, formal educational outcomes for looked-after children at the age of sixteen had improved. Support for the education of looked-after children was organized around a small team of officers who liaised with social workers, teachers and others to build capacity within the relevant service to improve outcomes.

The second Local Authority, named Provincial, serves a larger geographical area, has no major conurbation, but does include smaller populous towns, and overall the population is similar to
Municipal. There are fewer than 500 looked-after children within Provincial authority. In the three years before the research took place, educational outcomes for looked-after children had remained stable. The model of support here for looked-after children's education was characterized by a larger central team compared to that present in Municipal, and staff in this team engaged in direct work with children, as well as with staff from all services to promote the educational outcomes of looked-after children.

In accordance with the ethical research principles of autonomy, beneficence and justice [18] permission to carry out the project was granted via formal university ethics procedures. The Director or Deputy Director for each local authority acted as the gatekeeper. Participants volunteered themselves for the study or agreed to take part when approached. At the start of each interview, the participants were told they did not have to take part in the interview, or could end the interview at any time, with no negative consequences at all. Participants were also reminded that the researcher was not seeking to uncover 'right' or 'wrong' answers, but to explore the questions with them. Particular care was taken to reassure the two young people who took part in the research that the aim of the study was not to arrive at some predetermined or universal 'truth' but to listen to and value their experiences.

The fact that the interviews were conducted by an insider researcher with a background working with looked-after children, led to probing of responses to elicit rich data, and assisted in encouraging participants to produce honest responses within a safe environment [19]. The local authorities and participants within them have been anonymized, and pseudonyms have been created to protect identification of individuals.

Across both authorities, semi-structured interviews were undertaken with a total of 30 participants as set out in Table 1 below. The social workers and teachers involved in the interviews directly supported looked-after children. The role of the Virtual School Headteacher is to co-ordinate the educational support for looked-after children within their area, working with schools as well as social care staff to augment the educational journey of looked-after children. The central looked-after team staff are employed by the local authority to provide support and advice to staff and looked-after children.

The interview questions were constructed with reference to the research questions, and were designed to elicit a conversation with participants. All interviews were digitally recorded and transcribed verbatim. Key local authority documents regarding educational support for looked-after children were studied in order to gain organizational context. 
Table 1. Summary of interviews undertaken

\begin{tabular}{|c|c|c|}
\hline $\begin{array}{c}\text { Type of } \\
\text { interview }\end{array}$ & Municipal & Provincial \\
\hline Group & $\begin{array}{l}5 \text { social } \\
\text { workers } \\
3 \text { carers }\end{array}$ & $\begin{array}{l}6 \text { social } \\
\text { workers } \\
4 \text { carers } \\
2 \text { care leavers }\end{array}$ \\
\hline Individual & $\begin{array}{l}1 \text { Deputy } \\
\text { Director } \\
\text { Children's } \\
\text { Services } \\
1 \text { Virtual } \\
\text { School } \\
\text { Headteacher } \\
2 \text { Teachers } \\
\text { (One primary, } \\
\text { one high } \\
\text { school) } \\
1 \text { central } \\
\text { looked-after } \\
\text { team member }\end{array}$ & $\begin{array}{l}\text { 1 Deputy } \\
\text { Director } \\
\text { Children's } \\
\text { Services } \\
1 \text { Virtual } \\
\text { School } \\
\text { Headteacher } \\
2 \text { Teachers } \\
\text { (One special, } \\
\text { one high } \\
\text { school) } \\
1 \text { central } \\
\text { looked-after } \\
\text { team member }\end{array}$ \\
\hline
\end{tabular}

For analysis, the research questions were used to frame themes which were conceptualized and written using open language, so as to avoid too narrow an interpretation of the data. Code numbers were attached to each theme, with letters representing subthemes. The data were then hand-coded on the transcripts. Notes were made of the key points from published local authority material which corresponded to the research questions.

\section{Findings}

Seven key findings can be identified as follows. First, in response to the research question regarding the dispositions towards and enactments of national and local policies, there was a focus by staff on the relationship with the child rather than an unthinking implementation of policy. Staff demonstrated a deep commitment to their work and to the children with whom they worked. The following quotation is representative of the responses of frontline participants from education in response to being questioned about their use of policy: 'the driver is about just ensuring that we do the best for each child' (Dawn, Teacher, Primary School, Municipal). A similar perspective emerged from social care workers, one of whom stated that they 'prioritise what we see as important... which to us is the groundlevel' (Jenny, Social Worker, Municipal). The focus of carers, too, was not on high-level policy and paperwork, but on capturing the richness of interactions using their 'daily sheets' (Maggie, Carer, Provincial) or a 'day-to-day diary' (Laura, Carer, Municipal) to capture the texture of their detailed work with the children.

Where staff did use and refer to a range of policies, there was disagreement about which were most important for them. As might be expected, education workers focused more on educational aspects of legislation and on target-setting, while senior managers were more pre-occupied with meeting the demands of external policy imperatives compared with frontline staff, being mindful of the consequences for perceived failure: 'we get scorecards, and we get government intervention if we don't get it right' (Brenda, Deputy Director, Provincial).

Secondly, data related to the question regarding the dominant conceptualizations of looked-after children, indicated that the development of deep relationships with children led to staff focusing on meeting the children's holistic needs. Staff were keenly aware of the long-term impact of pre-care experiences upon children and their education, and as a result of this, the socio-emotional needs of children were seen as equally important as their educational needs. Educational success, while clearly valued, was not, as one participant put it, 'the be all and end all of everything' for every child (Jaz, Social Worker, Municipal). Another participant explained that once the relationship is established with the children, it can lead to a shift in the formal role, as they 'tend to just tell you things that are happening ...so you can be an advocate for the young person' (Pauline, Central Looked-After Team member, Provincial).

A very powerful illustration of the connection made by staff towards the children is seen in the following extract: 'I just thought "Oh, she's so lovely"... and she was in the library just laying on a cushion reading with her glasses on, and I thought "Yeah, we had to take you out of your home and we were the ones that saw the bruising", and so we went through the whole thing... when you're involved in the whole process... all you would ever want is that [progress] carries on'(Dawn, Teacher, Primary School, Municipal). Importantly, this disposition was supported by published documentation within both local authorities, reinforcing this stance.

Building upon this, a third finding was that staff not only saw meeting the emotional needs of certain looked-after children as equally important to their educational needs, but as a priority. As one participant put it, the prime aim of her role with looked-after children is to 'nurture, to care, and to make them feel loved and secure' (Laura, Carer, Municipal). This is because what was seen as important was a 'stable, family environment: somewhere they can have a stable base to go on 
from; somewhere they can understand how family and positive relationships work, 'cos [sic] otherwise they're just going to go out and model the relationships they've seen (Gillian, Carer, Municipal) This disposition of staff is further illustrated by the experience of Claire (Young Person, Provincial). When she was taken into care, she was moved from her home town in an effort, she believes, to separate her from perceived negative influences and so maintain her emotional stability.

This focus on addressing the ongoing impact of pre-care trauma for some looked-after children is exemplified by the following extract: 'many of these children would be actually deemed to be, if they were adults would be ill, they would be signed off, they would not be in a position to function properly, but we expect children to function properly within that environment (John, Virtual School Headteacher, Municipal). His counterpart stated that 'if there's that emotional baggage and that trauma then that has to be dealt with' (Chris, Virtual School Headteacher, Provincial).

These dispositions led to an impetus, shared by all staff at different levels of seniority, to recognize and celebrate relatively minor achievements of children at formalized events where children received certificates. The achievements recognized ranged from not only 'academic stuff' but also 'swimming or just that they've gone to school every day' (Tracy, Social Worker, Provincial). The focus was on supporting and encouraging looked-after children by boosting their confidence and sense of self-worth, as part of meeting the socio-emotional needs of the child. There was an interest in progress made, or 'the distance travelled for the individual' (Pauline, Central Looked-After Team member, Provincial) rather than in narrow test outcomes alone. The focus was on what staff felt was best for the child: "we do the job and we do it for the child...child-centred, we are, we want the best for that young person' (Charlie, Carer, Provincial). Once more, this approach was reinforced by official local authority documentation in both research sites.

This focus on addressing the emotional life of looked-after children did not mean, however, that staff ignored the 'real world' importance of education for young people. A fourth key finding was that staff held a broad interpretation of educational success, which included such factors as attendance at school, the development of positive social skills and relationships, better self-esteem or confidence, and the acquisition of basic skills. As one participant put it 'if you can't read, and you can't write, you can't get a job' (Sally, Deputy Director, Municipal). If staff could contribute to young people leaving school with attributes that would assist them in securing and maintaining employment, then that was seen as successful, even if the young people had not met the expected targets of achievement. Both young people interviewed in Provincial echoed this, referring to successful education as being, for them, relative to the ability and ambition of the individual. For staff within education, the idea of seeing children making progress with their formal educational performance, from an assessed baseline, was a significant aim of their work.

The wider context of the work was also significant. A fifth key finding, flowing from the research question on how individual and institutional levels of practice are related, was that the physical geography of the local authority impacted upon the children's learning where they had to travel long distances to and from a care placement and school:

'the kids are tired after an hour and half taxi journey' (Bob, Teacher, High School, Provincial) and these long journeys were 'hard to sustain' (Maggie, Carer, Provincial).

The visceral impact of these journeys was powerfully illustrated by Holly (Young Person, Provincial) who described how at the age of fifteen, she was placed some fifty-five miles from her home town and was expected to travel 'by buses three hours each way' to school. She went on to describe the experience as 'really, really difficult' and 'quite scary in the winter, it was late nights going back when it was dark and having to change buses'. Unsurprisingly, Holly struggled to prioritize her learning, and this only changed when she moved back to her home town, where, as she put it, she 'was able to manage education better, because I was not having to do that journey as well'.

Within Provincial local authority, the geography was particularly impactful. Staff described how time taken travelling to visit young people, who could be placed up to two hours' drive away from their base, reduced time for other work. The impact upon communication with colleagues from other agencies was also affected by distance, and setting up meetings took much longer as staff struggled to find a convenient time or place to meet.

Access to resources to support looked-after children was another key issue. Therefore, a sixth key finding was that different groups of staff had access to differing levels of resourcing. For example, social care staff felt that restrictions on funding led to them being unable to carry out meaningful or enriching activities or direct work with looked-after children, instead having to substitute these with, for example, visits to the local park. This presented difficulties associated with poor weather or teenagers seeing this as inappropriate. As one participant put it, they would like to be better supported in building their relationships and direct work with the young people, and if 'the organization starts thinking of these things as tools rather than just an expenditure that needs to be clamped down on, I think the better it will be for the young people we work with (Dev, Social Worker, Municipal). 
School-based staff, however, were able to access funding from various sources, including directly from the school budget to pay for additional tuition or international trips for looked-after children. One participant (Dawn, Teacher, Primary School, Municipal) explained how in her school a teacher is taken off timetable for two days a week specifically to support the needs of looked-after and other children with additional learning needs. Another participant (Rita, Teacher, Special School, Provincial) explained how the school had held a series of fêtes and other events to raise funds to refurbish a sensory room.

The final key finding relates to the research question about how the relationships between different services that support looked-after children are characterized. Here, the significance of inherent barriers to multi-agency working came to the fore. Staff from different agencies held different perceptions of children's needs. For example, social care staff felt that some schools tended to label looked-after children as 'trouble' rather than try to understand their vulnerabilities. Martin (Social Worker, Municipal) provided a detailed example of a looked-after young person who had committed a sexual offence and, having received a community sentence, was ready to return to education, only to face resistance from the school who were arguing that it was 'too risky' for the other pupils, and yet for Martin this was indefensible, as 'those risks should be managed: there's funding there to manage them'.

Issues of status and power were also powerful influences on multi-agency relationships, and there was some mistrust between workers in different agencies regarding, for example, professional judgement of how to respond to a child's situation. Jenny (Social Worker, Municipal) explained how she felt undervalued when a teacher insisted a child was subject to an independent specialist assessment to 'prove' that she had attachment difficulties before the school could then adapt their approach to handling the child's behaviour. Jenny felt that her knowledge and judgement as a professional was not recognized in this scenario, and she tried to insist to the teacher that 'as a social worker, I can tell you that this child has evidence of attachment issues and you need to be responding to her in a different way to what you're doing'. These inter-agency disagreements resulted in tensions between parties and ongoing challenges.

\section{Discussion}

Seen through a Bourdieusian lens, these seven key findings reveal that staff were focused on developing the embodied cultural capital of children with whom they worked, capital which staff believed would enhance the young people's life chances. However, educational needs were also seen as important, and where staff believed that educational success was important for the child's trajectory, they very much supported this acquisition of institutional cultural capital in the form of test and examination results. However, cognizant of the fact that for many children, these formal outcomes remain unattainable, and keen to nurture the young person's emotional needs, staff encouraged the acquisition of what might be called quasi-institutionalized cultural capital: certificates relating to the relatively minor achievements of the young people but nevertheless which may be useful for them in the future.

This focus on recognizing minor achievements could, paradoxically, reinforce low expectations of children. In supporting the development of embodied cultural capital and in meeting the child's socioemotional needs, staff wanted very much to encourage and support any noted advancement, however small. In doing so, they were in danger of inadvertently placing emphasis on achievements which, in the wider fields of education and employment, held very little value compared with the more legitimized achievements of school test and exam results.

The findings are therefore complex. They do not support the conclusions of much of the dominant research that staff are not committed to education [10], or that staff naively hold low expectations of looked-after children. Rather, staff involved in the research reported in this paper worked hard to meet the perceived individual needs of the children, balancing their socio-emotional and educational needs. The former took precedence where staff believed that to be necessary in order to help build embodied cultural capital as a springboard to then allow the child to settle and achieve within the educational field. The paradox here is that although staff appear to be highly committed to their work and child-centred, in doing what they believe is the 'right' thing (supporting socio-emotional needs and helping children acquire embodied and quasiinstitutionalized cultural capital), they may simultaneously be doing the 'wrong' thing (not focusing on hard test and examination outcomes or the acquisition of formal and widely recognized institutionalized cultural capital).

The varied perceptions and perspectives between staff operating within different services reflected the nature of the institutional habitus at play in both research sites, which was a complex mix of consensus (on the focus on the 'whole' child, and on securing the emotional stability of the child as a priority) and of contrast (individual staff interpretations of educational success and of which needs to address). In addition, the physical geography of the local authority and differential access to resources by staff impinged directly upon children's educational trajectories. 
The difficulties faced by some staff in accessing appropriate resources and dealing with the unavoidable barriers to, and restrictions in, multiagency working highlight the inherent limitations to what substitute care can achieve, or can be expected to achieve, in comparison to effective care provided by birth parents. Staff operate within a bureaucratic system characterized by a 'tick-box' mentality 'where practice has become more standardised, routinised and fragmented' [20]. Furthermore, the unavoidable nature of wage-labour whereby workers are employed in a particular capacity for a set number of hours per week limits what is possible for them to achieve [20]. There is a need to bear this in mind when the educational outcomes of looked-after children are considered in the round.

Taken together, therefore, the findings challenge the prevailing research narrative and support the alternative view that the long-term impact of damaging pre-care experiences should be taken into account along with the complexity of factors involved in explaining educational outcomes for looked-after children, resulting in the need to consider the progress made by such children [1].

\section{Conclusion}

This was a small-scale study, and therefore care is required before generalising the findings too readily to wider contexts. Nevertheless, broader conclusions can be arrived at with caution. The aim of the research was to explore the extent to which educational outcomes of looked-after children might be better understood using key Bourdieusian concepts such as cultural capital and institutional habitus. In this respect, the research contributes to a more subtle and complex understanding of reasons behind the educational outcomes of looked-after children. When the continued lower outcomes of this group is seen as a problem of the social reproduction of inequality, and when a Bourdieusian lens is used to examine the dispositions and actions of staff supporting these children, the dominant research narrative of the failure of the care system and blaming of staff can be challenged, and the complexity surrounding these educational outcomes begins to emerge. The fact that similar data emerged from the two very different local authorities adds weight to the findings.

In this research, staff worked hard to meet the individualized needs of children and to support them in the way they thought would best allow them to reach their potential, even if this did not lead to narrow educational success as measured in school test or examination scores. The inherent paradoxes here, where actions providing appropriate socioemotional support might preclude a focus on narrow schooling, further illustrate the nuanced nature of social reproduction at play. Staff do not ignore the importance of education through ignorance or wilful neglect of schooling, but tend instead to emphasize and enact their own interpretation of what the child needs, which could, ironically, lead to the child not acquiring the institutional cultural capital in the form of examination qualifications which would arguably help the child break the cycle of disadvantage.

In viewing the educational outcomes of lookedafter children at the level of the whole local authority, taking into account not only the motivations, attitudes and actions of frontline workers, but also the resources available, the inherent problems involved in multi-agency liaison and the resultant complexities and paradoxes, the intrinsic limitations of substitute care emerge and are reinforced as powerful determinants. The complexity that is laid bare here, by using the lens of institutional habitus, is that outcomes for lookedafter children do not appear to be simply the result of the actions or inactions of staff who support them, but rather reflect the whole local authority context.

Nevertheless, this should not lead to paralysis. Where staff supporting looked-after children have awareness of the wider unintended impact upon educational outcomes of a focus on socio-emotional support for children, of celebrating relatively minor achievements, of concentrating on progress made rather than final test outcomes, and of long journeys to and from school, they can use this knowledge to try to offer individualized support to looked-after child to augment their educational success. Staff are perhaps right to resist the 'standardized' approach, whereby children are measured against predetermined goals, and they are right to emphasise instead the uniqueness of each child with whom they work. However, while staff can and should support the 'whole' child, they need also to maintain an appropriate focus upon educational targets, given the central importance of recognized qualifications in enhancing the life chances of looked-after children in the social world into which they will be propelled upon leaving school.

\section{References}

[1] Berridge, D. (2007) 'Theory and explanation in child welfare: Education and looked-after children', Child and Family Social Work 12(1), pp. 1-10.

[2] Martin P. and Jackson, S. (2002) 'Educational success for children in public care: Advice from a group of high achievers', Child and Family Social Work, 7, pp. 121-130.

[3] Bourdieu, P. (1986) 'The forms of capital', in Richardson, J. (ed.) Handbook of Theory and Research for the Sociology of Education, Greenwood, New York, pp. 241-258.

[4] Bourdieu, P. (1977) Outline of a Theory of Practice, Cambridge University Press, Cambridge. 
[5] Bourdieu, P. and Passeron, L. (1977) Reproduction in Education, Society and Culture, Sage, London.

[6] Reay, D, David, M. and Ball, S. (2001) 'Making a difference?: Institutional habituses and higher education choice', Sociological Research Online, 5(4), pp. 126-142.

[7] Bourdieu, P. and Wacquant, L. (1992) An Invitation to Reflexive Sociology, Polity Press, Cambridge.

[8] Thomas, L. (2002) 'Student retention in higher education: the role of institutional habitus', Journal of Education Policy, 17(4), pp. 423-442.

[9] Fletcher-Campbell, F. and Archer, T. (2003) Achievement at Key Stage 4 of Young People in Public Care, Department of Health and Department for Education and Skills, Nottingham.

[10] Francis, J. (2000) 'Investing in children's futures: Enhancing the educational arrangements of "looked after" children and young people, Child and Family Social Work, 5(1), pp. 23-33.

[11] Coman, W and Devaney, J. (2011) 'Reflecting on outcomes for looked-after children: An ecological perspective', Child Care in Practice, 17(1), pp. 37-53.

[12] Forrester, D. (2008) 'Is the care system failing children?', The Political Quarterly, 79(2), pp. 206-211.

[13] McClung, M. and Gayle, V. ( 2010) 'Exploring the care effects of multiple factors on the educational achievement of children looked after at home and away from home: An investigation of two Scottish local authorities', Child and Family Social Work, 15, pp. 409431.

[14] Greig, A., Minnis, H., Millward, R., Sinclair, C., Kennedy, E., Towlson, K., Reid, W., and Hill, J. (2008) 'Relationships and learning: A review and investigation of narrative coherence in looked-after children in primary school', Educational Psychology in Practice, 24(1), pp. 13-27.

[15] Harkess-Murphy, E., MacDonald, J. and Ramsay, J. (2013) 'Self-harm and psychosocial characteristics of looked after and looked after and accommodated young people', Psychology, Health and Medicine, 18(3), pp. 289299.

[16] Phillips, R. (2007) 'The need for information on how the attachment difficulties of adopted and looked after children affect their schooling', Adoption and Fostering, 31(3), pp. 28-38.

[17] Berridge, D. (2012) 'Educating young people in care: What have we learned?' Children and Youth Services Review, 34(6), 1171-1175.

[18] Orb, A., Eisenhauer, L. and Wynaden, D. (2000) 'Ethics in qualitative research', Journal of Nursing Scholarship, 33(1), pp. 93-96.

[19] Mercer, J. (2007) 'The challenges of insider research in educational institutions: Wielding a double-edged sword and resolving delicate dilemmas', Oxford Review of Education, 33(1), pp. 1-17, 2007.

[20] Garrett, P.M. (2013) Social Work and Social Theory: Making connections, The Policy Press, Bristol. 